\title{
Clinicopathologic Case Reports
}

The editors of Ophthalmologica have felt the need of a new section for presentation of Clinicopathologic Case Reports. To this end eight pages will be set aside for two contributions on this subject ten times a year.

Ophthalmic pathologists are invited to submit manuscripts for this section to:

Dr. W. A. Manschot Ophthalmic Pathology Laboratory Medical Faculty Rotterdam Postbox 1738 - EE 993 Rotterdam (The Netherlands)

To orient the reader in reference to the author's contribution, a short introduction which should rarely exceed a few paragraphs should be placed at the beginning of the report.

T. The report should include a synopsis of the relevant clinical data, a macroscopic and microscopic pathological description and a comment which bears directly on the author's contribution. Macro- and micro-photographs are invited to illustrate the report. Legends to figures should be supplied as separate copy. 